\title{
Blucher
}

\author{
Blucher Proceedings \\ Cuba e Brasil no Século XXI (CBS21) \\ Ciência e Tecnologia na Sociedade do Conhecimento
}

\section{Impacto dos Portos no Desenvolvimento em Cuba e no Brasil}

\author{
Dra. Regina Oliveira ${ }^{1}$ e Dr. José Manuel Mateo Rodríguez ${ }^{2}$
}

\section{Introdução}

O setor portuário participa na determinação do grau de produtividade, competitividade, integridade e no desenvolvimento dos Países e regiões (Sanchez, 2004). Ao mesmo tempo, os portos desempenham um papel diferenciado nos processos de desenvolvimento a nível global, nacional, regional e local. Ao se constituírem em verdadeiros interlocutores sociais, nós espaciais, e pontos de atração de toda a atividade econômica e social, os portos desempenham um papel relevante na formação e no desenvolvimento territorial.

Contudo, o impacto dos portos no processo de desenvolvimento depende de um conjunto de fatores. Entre eles, merecem destaque, o caráter do próprio processo de desenvolvimento, as bases econômicas, o capital humano e social e as etapas históricas na formação territorial, os quais podem ser considerados também como os mais adequados indicadores para controlar seus impactos.

Ao analisar os impactos dos portos no desenvolvimento de Cuba e Brasil, é necessário ter-se em mente que, apesar de suas diferenças quanto às suas dimensões territoriais e ao grau e nível de desenvolvimento que apresentam, ambos os Países partem de uma base comum: o fato de terem sido economias dependentes de

\footnotetext{
${ }^{1}$ Universidade Estadual de Campinas (UNICAMP), Campinas, SP, Brasil. E-mail: reginacoliveira@ige.unicamp.br.

${ }^{2}$ Universidad de La Habana (UH), Academia de Ciencias de Cuba (ACC), Cuba. E-mail: mateo@geo.uh.cu.
} 
metrópoles coloniais, de Países hegemônicos e por terem passado por diversas etapas de estruturação política e econômica. Portanto, pode-se considerar que os impactos dos portos no processo de desenvolvimento dos dois Países e até mesmo os desafios atuais que enfrentam são semelhantes, de caráter homólogo e podem ser submetidos assim a uma análise comparativa.

\section{A Teoria e a Ideologia do Desenvolvimento}

O processo de desenvolvimento pode ser interpretado considerando-se três visões fundamentais:

1. Apreciação do crescimento econômico, como o seu elemento fundamental, dado o aumento da produção de bens e serviços, como resultado da instalação de um capital físico tangível.

2. A transferência dos benefícios do crescimento para atender às necessidades básicas da população e aumentar o nível e a qualidade de vida.

3. Otimização e aumento da complexidade funcional e estruturas aprimoradas das relações sistêmicas dentro dos territórios.

A maneira mais integral e concreta de articular essas três visões é considerar o território como portador do processo de desenvolvimento. Nesse sentido, se define o desenvolvimento territorial como o processo de articulação das estruturas políticas, sociais, econômicas e ambientais de territórios determinados (um País, uma região, uma província ou um município), para a mobilização mais completa de suas potencialidades, mediante processos relacionados com o alcance de certos propósitos (equidade, crescimento, sustentabilidade) que tenham o objetivo de garantir o bem-estar de sua população.

O desenvolvimento territorial pode se distinguido em quatro níveis: o global, o nacional, o regional e o local. Essa distinção depende da escala espacial pela qual se produz e se manifestam os processos de desenvolvimento.

Em relação à concepção de desenvolvimento, é fundamental ter-se em mente a noção de sustentabilidade e a própria concepção sobre Desenvolvimento Sustentável, independentemente de esta concepção encontrar legalidade na Cúpula do Rio de 1992. Na realidade, alguns anos antes, em vários encontros científicos e políticos organizados pelas Nações Unidas, foi criado o ambiente para sua oficialização.

Porém, a ideia de sustentabilidade é muito mais antiga, pois suas origens remontam à elaboração da Filosofia e da Teoria Sistêmica. Uma das maiores contribuições e ao mesmo tempo dificuldades do Desenvolvimento Sustentável têm sido 
introduzir uma visão sistêmica e orgânica do mundo em pleno momento de reinado do cartesianismo nas ciências.

O Desenvolvimento Sustentável implica na articulação de três padrões de sustentabilidade, inerentes ao sistema que se encontra em um determinado território: o econômico, o social e o ambiental. Alguns teóricos entendem essa concepção como o capital-natural, econômico e social, o que tem sido criticado por aqueles de visão mais radical. A concepção de Desenvolvimento Sustentável, em sua interpretação original e clássica, esteve fortemente sustentada no ambientalismo naturalista. De tal forma, se considerava que no desenvolvimento Sustentável, os sistemas econômicos e sociais deveriam se subordinar ou adaptar-se às características dos sistemas naturais. Isso se deve à preocupação com a contradição existente no desenvolvimentismo clássico, de fazer predominar a economia sobre a natureza (inclusive a sociedade deve conduzir a uma mudança radical em sua interpretação: para atingir a sustentabilidade nas ações econômicas se deve respeitar, antes de tudo, as características e os limites da natureza e da sociedade).

Independente das tentativas de considerar a sustentabilidade econômica, e ou social como o elemento fundamental da concepção de Desenvolvimento Sustentável, as opiniões atuais prevalecentes e oficializadas na última Cúpula sobre Meio Ambiente e Desenvolvimento (Rio +20$)^{3}$ celebrada em 2012, retomam a visão original de considerar-se a sustentabilidade ambiental, como "área de gestão", à qual devem adaptar-se os sistemas econômicos e sociais.

Nesse sentido, a sustentabilidade do desenvolvimento territorial implicaria em:

- Espaços ambientalmente sustentáveis, ou seja, as estruturas ambientais (espaços naturais racionalmente ocupados assimilados e apropriados pelas sociedades humanas), otimizados funcionalmente, com uma reprodução adequada dos recursos e serviços ambientais e com mínima degradação ambiental.

- Níveis de eficiência econômica e de eficácia social adequados e adaptados aos sistemas naturais.

- Governança territorial garantida, com uma harmonia entre as territorialidades inerentes aos diferentes agentes econômicos e atores sociais, e uma governabilidade participativa e efetiva por parte das autoridades estaduais.

\section{Os Portos e as Etapas de Desenvolvimento Histórico}

Quanto ao papel dos portos na construção do processo de desenvolvimento do Brasil e de Cuba, se pode distinguir ao menos quatro etapas:

\footnotetext{
${ }^{3}$ www.rio20.gov.br
} 
1. Primeira etapa: esteve marcada pela colonização de Cuba e Brasil, e coincide com a expansão generalizada do sistema capitalista, em sua fase inicial. Essa etapa esteve caracterizada fundamentalmente pela assimilação e ocupação dos territórios que se baseavam no apoio financeiro para a sua subsistência. A necessidade de comunicação com a metrópole motivou a instalação de alguns portos, geralmente vinculados às principais cidades. A fase inicial de abertura das atividades portuárias no Brasil foi levada a cabo, no inicio do século XIX, pela coroa portuguesa e registra a inserção do Brasil colonial no Sistema de Economia Internacional. Este processo esteve dirigido à expansão do mercado na exportação de materiais, tais como o ouro e a madeira, e a importação de especiarias e produtos manufaturados para a nobreza, e de forma mais especifica para atender o mercado de comercialização de escravos com o continente africano. Até meados deste século, se destacavam as atividades nos portos de Niterói (RJ) e Santos (SP). Durante este período, dois portos principais foram consolidados em Cuba: Havana e Santiago de Cuba. O primeiro teve uma função particular de porto-escala, garantindo o fornecimento de mercadorias às tropas e navios de guerra na transferência de bens da América-continente para a Espanha (a chamada "Frota das Índias"). O segundo teve uma função importante e estratégica de comunicação com as Antilhas, América Central e América do Sul.

2. Segunda etapa: se estende pela segunda metade do século XIX, em que se consolida o cultivo açucareiro e de outros produtos agrícolas. A mesma característica se apresenta nos dois Países, com o proposito de emergir uma economia de agro-exportação, responsável por garantir bens e matérias primas em larga escala para a metrópole e potenciais hegemonias coloniais. Formaram-se então as cidades portuárias, onde a sua função primordial consistia em ser pontos de entrada e saída, de um sistema geométrico projetado de forma homogeneizada e uma estrutura hierárquica de assentamentos, o que permitiu a produção, transformação, transferência e exportação de bens. Além disso, tinha a função de importar bens manufaturados para o consumo das elites urbanas e das oligarquias agrárias. Produziu-se então um crescimento econômico seletivo que deu lugar a uma significativa polarização e segregação espacial. Estabelece-se assim uma estreita relação porto/hinterlândia e as bases da diferenciação regional. Em geral, os portos constituem-se nos principais nós urbanos, e de toda a estrutura espacial do País. No Brasil, embora o açúcar tenha tido uma importância significativa nos primeiros anos de inserção econômica no mercado externo, é a partir da consolidação da produção e comercio do café com a América do Sul, América do Norte e Europa que, por volta de 1869, o governo imperial estabelece a primeira lei de concessão de exploração de portos pela iniciativa 
privada, definindo de forma clara a conjunta expansão entre as atividades portuárias e a organização do complexo ferroviário, por meio do traçado de ferrovias interligando as principais áreas produtoras de café, principalmente nos Estados de São Paulo e Minas Gerais ao Porto de Santos-SP. Atrelada a essa iniciativa tem-se a instalação de vilas e povoados ao longo das ferrovias que rapidamente se organizam como centros comerciais e mais tarde em importantes centros urbanos, tal qual o aglomerado urbano já definido nos limites de acesso e nas áreas de influência portuária. Essa fase crescente da expansão das atividades portuárias se estende pelo menos até meados do século XX, alicerçada no aumento da inserção de investimentos da iniciativa privada na produção, comercialização e gerenciamento das atividades portuárias, quadro que resulta no acúmulo de capital e enriquecimento de uma parcela diminuta da sociedade e uma ausência de governança pelo poder público vigente, definindo um quadro de declínio que se estende durante o século XX. Em Cuba, a plantação de açúcar, promovida a partir de meados do século XVIII, não consegue estabelecer-se, devido à influência das atividades agrícolas com o uso de tecnologia industrial atrasada. Apenas dois portos adquirem uma categoria relevante, Havana e Santiago.

3. Terceira etapa: está associada com a modernização industrial e a ocupação generalizada de ambos os Países, na fase de entrada na etapa fordista-taylorista do capitalismo, com o predomínio de sistemas rígidos no contexto do Estado-Nação e de economias de escala. Nesse sentido, os portos passam a adquirir um papel estratégico em que, associada à função de saída e entrada de produtos e da aglomeração urbana, observa-se a ampliação da produção industrial manufatureira e a substituição de algumas importações. Formamse então os distritos e as zonas industriais, articuladas entre os portos, as cidades e alguns aeroportos. Estabelecem-se assim alguns portos distantes dos centros urbanos, e outros especializados não vinculados às grandes cidades. A organização espacial vai definindo um caráter mais integrador. A implantação de sistemas viários, ferroviários e a conexão aérea permitem que a rígida diferenciação regional vá adquirindo um caráter de maior interrelação e integração nacional ou macro regional. Não obstante, as grandes cidades portuárias vão se convertendo em nós no âmbito nacional e vão assumindo espaços periféricos marginalizados, não diretamente vinculados aos espaços das grandes plantações. Essa etapa, no Brasil, é marcada por importantes períodos de transições políticas e econômicas. Em fins do século XIX, em 1889, com a Proclamação da República, intensificam-se as ações de privatizações portuárias resultando na ampliação de instalações e redes comerciais. Assim, durante o período monárquico e as primeiras décadas da República, os portos passam a representar importantes fontes de renda e po- 
los de atração urbana e comercial. A partir da revolução da Aliança Liberal, em 1930, seguida da organização do "Estado Novo", em 1934, observa-se mudanças significativas no quadro de gerenciamento das atividades portuárias que a partir de então, passam a ser estatizadas, entendendo-se então as atividades portuárias como fator de desenvolvimento econômico nacional. Em 1964, com o governo militar, as ações de desenvolvimento vão culminar na organização da Empresa de Portos do Brasil/SA (PORTOBRAS), tendo definido o caráter monopolista do Estado sobre os portos. Nesse período, cabe ao Estado a gerencia e a operacionalização das atividades portuárias, desde a normatização e fiscalização trabalhista até a definição das normas de uso das instalações relacionadas ao porto, culminando em um quadro de excessivas normas, de burocratização, de altos custos de operacionalização e de uma flagrante ineficiência. Esse quadro se estende até 1993, com a extinção da PORTOBRAS e a definição da Lei Federal n ${ }^{\circ} 8630$ que diz respeito à política de modernização dos portos, sendo retomada assim as políticas de desenvolvimento nacional, reconhecendo-se as áreas portuárias como um mote importante para o avanço do comercio e das relações exteriores, levando à implementação de capital e de ampliação e instalação de tecnologias nas áreas portuárias, bem como a busca pela redução das ações burocráticas e maior agilização das transações comerciais e, de forma mais expressiva, a retomada das ações de privatização. Há de se destacar, que as ações de modernização não se processam de forma igualitária ao longo do vasto território brasileiro, culminando em situações conflitantes, seja no uso de instalações obsoletas, seja na má articulação logística comercial. No inicio dos anos de 2000 o Governo Federal lança um programa denominado "Agenda Portos", tendo como objetivo inicial diagnosticar os principais problemas de diferentes ordens de prioridades no setor portuário, para então definir ações conjuntas entre Governo Federal, Estados, Municípios e a iniciativa privada, motivados pela necessidade de melhoria dos processos de escoamento da produção agrícola, industrial e mineral vinculados à exportação e importação de mercadorias, definindo assim uma nova ordem de inserção do País no circuito econômico em escala mundial. Em Cuba, após a extinção do regime colonial espanhol, a produção agrícola se consolida, e o papel dos portos é reforçado como pontos de entrada e saída, especialmente nas três principais cidades portuárias (Havana, Santiago de Cuba e Cienfuegos). Embora ainda existam outros centros, estes permanecem em baixa atividade, como Isabela de Sagua, Matanzas, e Antilla. Com a revolução socialista, se reforça o sistema e cria-se novos portos especializados. E alguns se convertem em polos de desenvolvimento, de diferentes ordens. Em geral, se associam a um período de uma marcada industrialização, a uma ampliação da produção açucareira e à 
criação da plantação de citros, com o propósito de atender aos compromissos internacionais devido a integração do País ao CAME - Conselho de Ajuda Mútua Econômica.

4. Quarta etapa: esta etapa vai se estabelecendo a partir do final do século XX. É o momento em que se forma uma nova estrutura geopolítica, com o colapso da contradição ideológica entre os campos políticos e militares, em que se estrutura um novo sistema mundial, devido à incidência da globalização econômica. Forma-se então um espaço global de fluxos comerciais e de comércio, uma nova economia de circulação, no contexto do modelo pós-fordista, seguindo-se de uma nova expansão global do capital. A multilocalização da produção levou à pulverização do desenvolvimento industrial, à criação de redes de empresas e empresas em redes, a territórios produtivos de diversos tipos ao redor do mundo: distritos de pequenas empresas, polos tecnológicos, conjuntos produtivos locais, zonas francas de grandes dimensões, plataformas logísticas que dão lugar à produção de bens e serviços em diferentes Países e lugares. Na medida em que os intercâmbios internacionais de mercadorias são preferencialmente realizados por via marítima, os portos ocupam uma posição estratégica no centro dessa economia de circulação. Nesse contexto, os megaportos vão adquirindo um novo papel ao viabilizarem a circulação de pessoas e de volumes expressivos de mercadorias. Em tais condições, se privilegiam fatores como localização, o grau de especialização da mão de obra, as condições de acessibilidade, a proximidade de um mercado de consumo de grande porte, a estabilidade institucional, entre outras. Produz-se assim uma verdadeira revolução no sistema de transporte marítimo com a incorporação de novas tecnologias tais como os grandes navios Pós-Panamex, capazes de transportar enormes quantidades de cargas, e a expansão de containers para transporte de mercadorias. Constrõem-se novos portos, localizados a relativa distância dos grandes centros urbanos, e não associados por completo a novas estruturas urbanas. Assim, os portos se convertem em polos de desenvolvimento, ao redor dos quais se localizam verdadeiros complexos industriais portuários, distritos industriais, zonas comerciais, assim como zonas francas, zonas de desenvolvimento, e outras figuras que propiciam a flexibilização e um controle menos rigoroso por parte dos Estados Nacionais, outorgando-se maior prerrogativa à iniciativa privada. Isso traz mudanças significativas nas estruturas ambientais espaciais e territoriais dos Países. Isso porque se altera a relação anterior entre porto/hinterlândia, sendo que o porto passa a ser produto de interações locais, regionais, nacionais e internacionais que se estruturam de maneira diferenciada no espaço e no tempo.

$\mathrm{Na}$ atualidade, o Brasil realiza aproximadamente 95\% do volume total de im- 
portações e exportações provenientes dos portos, totalizando cerca de nove milhões de toneladas de mercadorias distribuídas nos serviços dos 37 portos então existentes, considerando-se tanto portos de natureza marítima quanto fluvial. Dentre as principais demandas emergenciais que impulsionaram a redefinição das ações portuárias no Brasil nos últimos anos, têm-se as novas frentes de exploração de natureza mineral, como o petróleo e o pré-sal, definindo a necessidade de ampliações estratégicas e/ou abertura de novas frentes, como os portos de Suape no Estado de Pernambuco, Pecem no Estado do Ceará e Açú na região norte do Estado do Rio de Janeiro. Estas alterações se devem, entre outros fatores, à incorporação de mudanças tecnológicas, à expansão da automação das operações, à definição e gerenciamento integrado de centros logísticos além de circuitos econômicos que extrapolam os limites locais e regionais sob uma perspectiva mais global.

Em Cuba, a construção do novo Porto de Mariel e a implantação da Zona Especial de Desenvolvimento Econômico de Mariel (ZEDM) a 45 quilômetros de Havana, capital do País, constituirá sem duvida um momento fundamental em seu processo de desenvolvimento. O Porto dará a oportunidade única de inserção de Cuba às cadeias produtivas globais, desempenhando assim um papel central na intensificação do comércio no Mediterrâneo Americano, no transporte e translado de mercadorias que se produzem como resultado da ampliação do canal do Panamá, e a possível construção no futuro de um porto inter-oceânico na Nicarágua.

O Porto de Mariel contribuirá com a abertura e a maior inserção de Cuba na economia e no processo de globalização em seu sentido mais amplo. Isto representará um estímulo para as cadeias produtivas a nível macro-regional e nacional, e para a reestruturação do processo de industrialização do País, criando assim uma ligação estratégica de Cuba com a nova reconfiguração geopolítica regional e global, na medida em que o País constituirá um nó importante na rede de portos marítimos estabelecendo-se assim as raízes de um novo regionalismo latino-americano no sistema dos BRICS.

Não obstante, o sistema portuário, tal e como tem sido concebido ao longo da história, deverá continuar existindo, modernizando-se, e em alguns casos trocando de funções, como em Havana, que se converterá em um centro portuário de funções turísticas.

\section{Um Balanço da Incidência dos Portos no Processo de Desenvolvimento no Brasil e em Cuba}

Do ponto de vista espacial, o desenvolvimento tanto no Brasil como em Cuba tem apresentado as seguintes características:

- Altera-se o equilíbrio espacial e territorial devido ao aumento ou permanência das diferenças entre os centros e as periferias; formam-se espaços periféricos 
e marginais em torno dos enclaves, e das redes de conectividade. O sistema de assentamento urbano, coerente, espacial e paisagisticamente equilibrado, será em grande parte alterado.

- Produz-se uma concentração espacial, econômica, demográfica e política, provocando uma metropolização parcial, com um ou vários megacentros de dimensões desproporcionais, privilegiando uma migração anárquica.

- Altera-se o espaço equilibrado, com altos níveis de conectividade e de integração em todo o País, desarticulando os nós que potencializam os fluxos em uma hierarquia racional e macro-regional.

- Considera-se a localização, distribuição e organização de mercados de bens e serviços irregulares em todo o País, devido à hiperconcentração econômica, à segregação espacial e à debilidade dos centros de convergência de serviços e espaços públicos.

- Inexistem programas de permanência da população nestas regiões, com ofertas de empregos e oportunidades, de tal maneira que não se consolida uma identidade territorial coerente e maneiras de assegurar a equidade e a inclusão sócio-espacial. Ao constituir centros de concentração econômica, demográfica e social, os portos contribuem de maneira significativa para a intensificação dessa situação. Assim, o problema espacial fundamental do processo de desenvolvimento, tem sido que os sistemas territorial e ambiental atualmente existentes não podem servir como ponto de partida racional e coerente para a implantação de um desenvolvimento sustentável.

\section{A Refuncionalização dos Portos e a Busca de Equilíbrio no Desenvolvimento Territorial}

No intuito de buscar uma incidência efetiva dos portos no processo de desenvolvimento, e minimizar os problemas anteriormente mencionados, se considera pertinente analisar algumas ideias levando-se em conta distintos níveis espaciais. Para isso, consideramos o desenvolvimento sob uma perspectiva territorial:

- Em nível global, além de contribuir para o aumento do crescimento econômico através de um maior intercambio comercial e da reorganização da produção industrial, os novos megaportos contribuem para uma maior articulação espacial. É obvio que o desenvolvimento global está adquirindo, nesta etapa, um caráter mais globalizado, com inter-relações espaciais muito mais intensas. No Brasil, os novos portos contribuem para uma participação mais ativa com 
os Países do MERCOSUL, no comércio com Países do Norte e Mesoamérica, e com o resto do mundo. Para Cuba, o porto de Mariel abre a possibilidade de constituir-se em um dos quatro portos do Caribe que serão nodais em seu funcionamento, para a incorporação dos fluxos de intercâmbios que estão se revitalizando entre a Ásia, os Países da Mesoamérica, Sul-americanos e Norte-americanos, e com a Europa.

- Em nível nacional, os novos megaportos constituem-se em pontos de entrada e saídas de bens e serviços, significativamente ampliados, além de constituírem um ponto agregador de valor, promovendo sem dúvida um impulso ao crescimento econômico e ao desenvolvimento em nível de todo o Estado-Nação. Se esses impactos apresentarem reflexos mais imediatos nas regiões mais próximas, estimularão a conectividade, os fluxos e a difusão espacial dos intercâmbios. E se converterão assim em um sistema de fluxo de energia, matéria e informação que permitirá assegurar a sustentabilidade dos processos econômicos, sociais e ambientais no âmbito do País. A criação de polos de modernização tecnológica, como política estruturante a nível territorial, como vetor de desenvolvimento regional e territorial e como modo de inovação, permite considerar a ciência e a tecnologia como componentes da competitividade sistêmica. Assim, espera-se que todas essas articulações devam refletir em efeitos positivos no processo de desenvolvimento territorial a nível nacional. No Brasil, o Plano de Aceleração do Crescimento-PAC instituído pelo Governo Federal a partir de 2007, prevê dentre suas metas a retomada do desenvolvimento nacional a partir do planejamento e execução de grandes obras de infraestrutura social, urbana, logística e energética. Nesse sentido, as atuais obras de construção e ampliação das redes portuárias bem como o fortalecimento das relações externas com a abertura de novas frentes comerciais vêm atender as principais demandas de crescimento econômico do País. A formação das redes multimodais que considerem a integração dos setores rodoviários, hidroviários, portuários e com menor ênfase os ferroviários, tem sido uma das principais metas no setor de transportes, tendo como perspectivas a agilização da mobilidade interna entre a produção, distribuição e escoamento da produção nacional. Espera-se que a implantação dos projetos previstos no PAC para o setor de transportes venha minimizar os impactos catastróficos revelados ao longo de décadas de baixos investimentos e planejamentos no setor em âmbito nacional, fato que tem representado um desafio dado não apenas o volume de investimentos necessários, bem como a vasta extensão territorial e substancialmente os diferentes fatores de ordem política, econômica, social e ambiental que estão associados à expansão deste setor. Em Cuba, praticamente até 1960 os portos se inseriram no modelo de crescimento econômico capitalista, estando dependentes da estrutura da 
produção açucareira. Os portos cumpriam o papel de portas de estrada e saída de bens, e garantiam o funcionamento do sistema econômico e social segregador e explorador. Com o modelo de socialismo estadista, instaurado pelo processo revolucionário, a produção agrícola se ampliou de maneira considerável, acompanhada de certa industrialização e diversificação. Nesse sentido, muitos portos se converteram em polos e micro polos de desenvolvimento, permitindo atividades de processos produtivos, dando lugar à ampliação da função de portos de entrada e saída. A construção da mega obra de Mariel coincide com uma mudança significativa do processo de desenvolvimento do País, mediante a implantação da "atualização do modelo econômico cubano", aprovada no VI Congresso do Partido Comunista de Cuba em 2011. Esta nova política estatal se caracteriza por uma significativa diversificação das orientações produtivas, onde a produção açucareira se reduz drasticamente. Assim, vai se adquirindo um caráter mais atual, com a participação na gestão territorial não apenas do Estado, mas das pequenas empresas privadas e das cooperativas. O porto de Mariel deverá significar uma maior abertura do País aos processos econômicos globais, com maior participação de empresas transnacionais e translatinas, e inserção ativa de Cuba nos macroblocos regionais. Quanto ao impacto destas mudanças no País, este será mais acentuado no Ocidente. Se trata de garantir a descentralização, a desconcentração e a existência de formas difusas de crescimento espacial. Isso deve favorecer a erradicação de efeitos positivos nas províncias centrais, especialmente aqueles no leste do País.

- Em nível regional, o propósito mais importante deve ser o de buscar um alto nível de interação entre o equipamento técnico e inovador e toda a estrutura empresarial dos portos, considerando a estrutura regional e territorial que serve de suporte para as atividades portuárias. Para isso, espera-se que os portos se convertam em espaço territorial de empresas transnacionais, dirigidas a usá-los como suporte a suas operações. Também há que evitar a exploração das regiões circundantes para a obtenção de ganhos a curto prazo que podem gerar degradação ambiental, pela exploração econômica, pela alteração do tecido social, cultural e espacial. É imprescindível, promover processos de governabilidade territorial, concebendo os territórios como espaços coesos, conectados e com identidades próprias, no contexto de múltiplas territorialidades formadas por um conjunto de atores sociais e agentes econômicos. Para isso será fundamental que as regiões polarizadas que se formam, assegurem uma estrutura espacial coerente com seu entorno. A história de implantação e expansão portuária no Brasil é marcada por diferentes níveis de impactos nas relações regionais em grande parte sentidos no modelo de concentração urbana, ocupação desordenada, e rápida 
desconfiguração da paisagem original, definindo situações de conflitos e impactos ambientais de diversas ordens de grandeza. Haja vista, que grande parte das regiões portuárias se consolidou em momentos anteriores a uma discussão mais abrangente quanto à possibilidade de um planejamento mais igualitário regido por leis ambientais com mínimo de criticidade de modo a minimizar as relações de conflitos, seja no âmbito das ações de apropriação do espaço definidas pela conjuntura política, económica e social vigente, seja pela impressão dessas relações na alteração da dinâmica de funcionamento dos sistemas naturais, resultando em alterações que extrapolam a escala de análise local e em alguns casos até mesmo regional. Nas últimas décadas, os planos de gerenciamento territorial, marcados pelas restrições legais impostas pela legislação ambiental, tem resultado em planos gestores que devem considerar as fases iniciais do projeto, instalação e execução das atividades, tendo como perspectiva minimizar os impactos nas diferentes fases. Em Cuba, os portos mais recentemente criados, têm trazido consigo um conjunto de problemas de caráter ambiental e espacial. Isso se dá devido à excessiva concentração urbana e econômica. Em alguns polos de desenvolvimento associados aos portos, observa-se a produção de uma ocupação desordenada trazendo como consequência a alteração da ordem espacial e a banalização paisagística, com a consequente desestruturação do equilíbrio regional. Para Mariel está prevista a elaboração de um plano de ordenamento territorial que, supostamente, deverá corrigir essas possíveis deficiências.

- Em nível local, o conceito de desenvolvimento enfatiza a centralização dos espaços locais, em que os processos de desenvolvimento territorial são liderados por parcerias com a comunidade, com base na apropriação e capacitação, fatores predominantemente endógenos. Nesse sentido, os portos tem um efeito duplo. Em alguns casos, a metropolização e a concentração espacial dos processos produtivos tem levado à alteração do tecido social local, ao ser absorvido pela dinâmica da atividade portuária. Em outros momentos, especialmente em termos locais e nas regiões circunvizinhas, a atração econômica dos portos tem estimulado processos econômicos de crescimento não comprometendo o enraizamento sócio cultural. Isso acontece no caso de sociedades locais capacitadas, geralmente associadas a pequenas propriedades bem estruturadas. Nos novos portos, em termos do desenvolvimento local, não há outra opção senão promover processos participativos e apropriação consciente de lugares por parte da população local. Devemos priorizar o empoderamento das comunidades para o uso racional dos recursos locais, promovendo a endogeneização e a transferência de lucros provenientes da exploração dos territórios afetados. O cenário local de implantação das grandes obras portuárias no Brasil nos últimos anos tem sido marcado pelas 
alterações na paisagem e nas relações de uso desses espaços, definindo novas formas de articulações, concentração de renda e serviços. No âmbito das relações locais, já na fase de instalação do projeto, se observa mudanças significativas no setor de comercio e serviços, levando a uma nova definição de organização espacial regida pela exigência do mercado que se forma. Há um contingente populacional que migra para os locais próximos à instalação dos projetos que, diferentemente do modelo de organização do inicio do século passado, esse novo contingente se constitui em sua maioria de técnicos e especialistas com poder aquisitivo suficiente para definir novas relações de consumo e de serviços, tendo a população local novos direcionamentos, seja na mobilização ou relocação de populações tradicionais, seja na alteração das relações cotidianas. Assim tem-se a curto prazo mudanças significativas. Em Cuba, em grande parte, o próprio desenvolvimento socialista deu lugar a processos de homogeneização espacial e social, e à dependência dos insumos definidos pelo Estado. Isto levou a uma alteração significativa da unidade e consistência das sociedades locais. Alguns, com falta de recursos, se dirigiram para a ocupação informal dos espaços com consequente banalização da paisagem. Este fato tem sido perceptível na vizinhança dos micro-polos de desenvolvimento. Com o modelo atualizado a partir de 2011, estas comunidades estão tentando promover processos de desenvolvimento local, muitas vezes com a participação ativa de intervenção estatal em níveis além dos locais. O entorno do megaporto de Mariel está formado por várias comunidades e pequenas cidades, que são caracterizadas por níveis relativamente baixos de qualidade de vida, com tecido social fraco e pouco coeso além de lugares desarticulados. É evidente que o desafio na construção do megaporto está em promover o processo de capacitação e endogeneização a nível local.

\section{Considerações Finais}

O sistema do mundo atual está sendo incorporado plenamente em um processo de ocupação intensa de maior fluidez espacial. O novo meio técnico científico informacional é um eixo inerente à globalização o qual se caracteriza da seguinte forma: "Com a globalização, a informação e as finanças passam a configurar a nova geografia distinguindo os lugares segundo a presença ou escassez das novas variedades-chave. Desta forma se agravam as diferenças regionais com o aumento da influencia da Região Central, com a hegemonia também (se dando) pela ocupação de áreas periféricas com produções modernas. O mercado, graças ao meio técnico científico informacional, se converte em um mercado global. O espaço total do País tem o território enquanto suporte de produção equivalente ao mercado. O País tem áreas onde a informação e as finanças têm uma influência 
maior ou menor, da mesma maneira que antes as questões se colocavam quanto aos produtos e a mão de obra. A informação e as finanças se fazem fundamentais na arquitetura da vida social" (Santos \& Silveira 2011). Os novos megasportos, constituem objetos nodais desta nova configuração espacial. São parte de uma realidade, em que alguns Países são rapidamente incorporados, e outros vão estar se movendo mais longe das novas dinâmicas globais. Brasil e Cuba estão apostando em entrar nesta nova configuração do processo de desenvolvimento. Salvados os efeitos perniciosos desse fenômeno, esta decisão comporta grande responsabilidade dos governos e das sociedades. O conhecimento e a produção humana consistente, tornam-se necessidade real, para evitar que toda a dinâmica espacial, que é o suporte do processo de desenvolvimento, não se forme de maneira espontânea, mas consciente e racional. Eleger uma sociedade do conhecimento, onde a sociedade e a ciência tenham um papel real e não virtual na tomada de decisões é uma exigência objetiva quando se pretende que o novo meio técnico científico informacional, em que os novos megaportos apresentam um papel central, se constituam da melhor maneira possível. O Projeto Cuba e Brasil Sociedade do Conhecimento para o século XXI $(\mathrm{CBS})^{4}$, promovida pela Academia de Ciências de Cuba com parcerias com instituições brasileiras, tem apostado em um papel ativo na construção do novo meio científico informacional, com o propósito de formar em ambos os Países processos de desenvolvimento sustentáveis, e que sejam realmente assimilados pela maioria das sociedades de ambos os Países. Nesse sentido, contribuir para considerar racional o impacto ideal para o desenvolvimento portuário em ambos os Países, tem sido considerado como um elemento fundamental para a colaboração entre cientistas dos dois países.

\section{Referências Bibliográficas}

SANCHEZ, R.. Puertos y transporte marítimo en América Latina y El Caribe: un análisis de su desempeño reciente. CEPAL, Dirección de Recursos Naturales, Santiago de Chile, 2004, 79 pgs.

SANTOS, M., SILVEIRA, M.L. O Brasil: território e sociedade no inicio do século XXI. Editora Record, Rio de Janeiro, 2a edição, 2011, 414 pgs.

Recife, Olinda, Maceió, 2014

\footnotetext{
${ }^{4}$ http://dgp.cnpq.br/dgp/espelhogrupo/7690648629288254
} 